\title{
Design and Construction of a Prototype Wireless Power Transfer Device
}

\author{
Oluseun D Oyeleke ${ }^{\mathrm{a}}$, Dr Sadiq Thomas ${ }^{\mathrm{b}}$, Dr Petrus Nzerem ${ }^{\mathrm{c}}$, Dr. GokhanKoyunlu ${ }^{\mathrm{d}}$ \\ ${ }^{a}$ Air Force Institute of Technology, Kaduna. Nigeria \\ ${ }^{b}$ Computer engineering department Nile University Nigeria \\ ${ }^{c}$ Petroleum and Gas Engineering Department, Nile University Nigeria \\ ${ }^{d}$ Computer engineering department Nile University Nigeria
}

Received: 17 August 2018; Accepted: 22 October 2018; Published: 08 March 2019

\begin{abstract}
This project is aimed at developing a prototype wireless charging system that allows for charging convenience using wireless charging also called inductive charging. This allows charging to be made easier and free from connecting leads between charger and handset.

In order to successfully achieve this task, the design of the prototype was developed in two parts, a transmitter with resonator and a receiver with resonator. The transmitter converts DC voltage to AC, and transfers energy wirelessly through an LC resonator to the receiver through mutual induction, and hence induces EMF in the receiver. The EMF is rectified, filtered and regulated and output is used to charge mobile phones.

Testing results and measurements taken on this prototype shows that significant amount of EMF can be induced at receiver through air coupled transformers due to EM waves at high frequencies. The charging distance is $3 \mathrm{~cm}$ maximum with end-to-end coupling.
\end{abstract}

Index Terms: Wireless charging, electromagnets, oscillators, inductive charging.

(C) 2019 Published by MECS Publisher. Selection and/or peer review under responsibility of the Research Association of Modern Education and Computer Science.

\section{Introduction}

Wireless power transfer is an emerging technology in the world of mobile phones. Imagine a scenario where one gets home and one can simply place his/her phone on a charging mat in his sitting room or in the kitchen or

* Corresponding author.

E-mail address: contactseun@gmail.com 
in his vehicle without having to plug in his phone to a charging source using wires. During emergency one canuse his hand free to communicate while ones phone is still charging. The convenience of wireless power transfer through the process of inductive coupling will change the way we charge mobile phones and other devices.

Wireless power transfer can be used to power electric cars, electronic gadgets for electronic warfare and electronic attacks. In future drones, Quad copters, UAV, wearable devices, body implants and other devices used by security personnel will be powered wirelessly.

We are in a wireless revolution, creating a world of wireless technologies is a possibility, a world where we are doing away with bio-degradable organic materials, a world where there will no more be bundles of wires, tangling up here and there, a neat world, where there will be invisible yet reliable interconnectivity between electronic components and their power source, wireless hardware, wireless keyboard, wireless mouse, Bluetooth, ZIGBEE, WLAN, WIFI are all aftermath of the emerging success of the current wireless revolution. Like a typical scene in a Sci-fi movie the world is gradually doing away with wires and using EM waves to establish connection.

The objective of this project is to design a prototype inductive wireless mobile phone power transfer charging system. The project exposes one to hand-on practical experience in building electronic circuits by appropriate choice of electronics devices and components. This also demonstrates the capability and practicability of wireless power transfer for charging electronic devices using mobile phone for demonstration.

\section{Literature Review}

\subsection{Review of Similar Works}

Bashrat 2013 [1]Proposed and developed an innovative charging techniques based on faradays law of electromagnetic induction where is EMF induced in coil, and the EMF induction is based on flux linkages between the two coils. The charging station produces energy and transmits it through the inductive coupler to an electrical storage. Time varying EM fields creates a coupling though anairgaphence forming an air core transformer and the rectified voltage from the secondary is used to charge the device.

Ibrahim 2017[2] paper showed an overview study and basis of the wireless mobile phones charging techniques where it was stated that wireless power transfer (WPT) can be defined as the electric energy transmit to an electric load from a power source without using a physical connection between them. WPT is allowing mobile devices to be continuously charged conveniently, easily and without constraints of using a power cord. Therefore an effective technique is demanded to enable energy transmission between charger station and users equipment without employing wire or other material .He also studied eCoupling an Fulton Innovation which is a bidirectional charging technology which would fundamentally permit someone to charge their mobile phone by simply putting it on the back of a tablet, .However there was no prototype developed as this was purely a survey work. International Journal of Electromagnetics and Applications

Elixabeth et all 2014[3] project is the creation of an inductive charging pad which allows a suitable, easy to use battery charging technique for mobile phones and other mobile devices. The work focuses on the problem of significant reduction of e-waste and de-cluttering of home and office space by eradicating the necessity for power cords via the employment of wireless power transfer systems. The 'Inductive Charging Pad', is a wireless power transfer method using inductive coupling to transfer electromagnetic energy from a charging station to handy devices. The project eliminates the need to constantly plug and unplug the device, with a successful implementation of this, the durability of the device would increase and its usage would become more convenient.

The contribution made in this research is to further take inductive charging to its practical realization by using a high efficiency power transmitter capable of delivering more voltage for inductive charging. This 
eradicates the problem of dead battery for mobile phones, wearable devices and supplies energy for remote charging of wireless sensor networks, wireless charging is set to change this by providing power wirelessly so that anywhere with the vicinity of the wireless charger the phone can charge continuously even while in use.

According to WiTricity Corporation, ${ }^{[4]}$ "wireless power transfer had succeeded to make these essential products more available, convenient, and reliable (in terms of availability of power to run them). The wireless power technology is very real"

\subsection{Fundamental Concepts}

\subsubsection{Mutual Inductance}

Induced EMF can be dynamically induced or statically induced, and therefore creating the ability of one coil or circuit to produce EMF in a nearby coil by induction when the current induced in the first coil changes [5], usually the conductors or coils remain stationery and the flux linked with it is changed by oscillation.

The self-inductance of each distinct coil is given as:

$\mathrm{L}_{1}$ and $\mathrm{L}_{2}$ self-inductance ${ }^{[6]}$

$$
L_{1}=\frac{\mu_{o} \mu_{r} N_{1}^{2} A}{\ell}
$$

and

$$
L_{2}=\frac{\mu_{o} \mu_{r} N_{1}^{2} A}{\ell}
$$

Then by cross-multiplying the above equations, the existence of the mutual inductance between the both coils can be expressed in terms of the self-inductance of each coil. ${ }^{[6]}$

$$
m=\sqrt{L_{1}} L_{2} \text { In Henrys }
$$

Hence giving us a final and more common expression for the mutual inductance that exists between two coils as: ${ }^{[6]}$

\subsection{Coefficient of Coupling}

$\mathrm{K}$ is called the coefficiant of coupling it is an expression of the fraction of the flux on one coil that will pass through the other coil, and itdepends on the portion of the aggregatelines of flux lines that cuts both windings in the primary and secondary ${ }^{[7]}$.If the flux due to one coil completely links the other then the value of $\mathrm{k}$ is unity but if there is no linkage then the value of $k$ is 0 .

When $\mathrm{k}=1$ coils are said to be tightly coupled and when $\mathrm{k}=0$ they are magentically isolated from each other and if $\mathrm{k}<0.5$ the two coils are said to be loosely coupled ${ }^{[8]}$.

Coupling factor between coils is given by Eqn 4

$$
\mathrm{k}=\frac{M}{\sqrt{L_{1} L_{2}}}
$$


Or

$$
\mathrm{M}=\mathrm{k} \times \sqrt{L_{1} L_{2}} \mathrm{H}
$$

When the coefficient of coupling, $\mathrm{k}$ is equal to 1 , such that all the magnetic flux lines of one coil cuts all of the turns of the other coil, the mutual inductance is equal to the geometric average of the two individual inductances of the coils ${ }^{[9]}$

\subsection{Oscillators}

An electronic oscillator is an electronic circuit that produces a periodic, oscillating electronic signal, often a sine wave or a wave. ${ }^{[10]}$ Oscillators are circuits that generate a voltage output waveform that is continuous at a selected frequency or frequency range, with the values of the inductors, capacitors or resistors forming a frequency tunable LC resonant tank circuit and feedback network. The output of an oscillator depends on the device parameters and external components. In LC oscillators a tuned circuit is used to select frequency of interest. The LC oscillator's frequency is controlled using a selective or resonant inductive/capacitive (LC) circuit with the resulting output frequency which is called the Frequency of oscillation.

An RLC circuit as shown in Fig. 1 is a common oscillator arrangement.

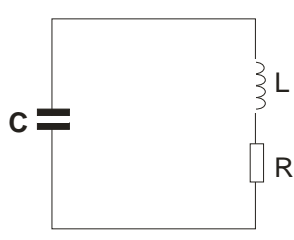

Fig.1. RLC Circuit

Solution to the $2^{\text {nd }}$ order differential equation is

$\mathrm{V}=\mathrm{V}_{\mathrm{o}} \mathrm{e}^{-\alpha \mathrm{t}} \mathrm{e}^{+\mathrm{jwt}}$

Equation indicates oscillatory sinusoidal wave $\mathrm{e}^{\text {+jwt }}$ having decaying amplitude with attenuation constant $\alpha$

The frequency output is given by

$\grave{\omega}=\frac{1}{\mathrm{LC}}-\frac{\mathrm{r}}{4 \mathrm{~L}}[10]$

To keep the oscillations going in an LC tank circuit, all the energy lost in each oscillation has to be replaced and also retains at constant level the amplitude of these oscillations. The simplest way of replacing this lost energy is to take part of the output from the LC tank circuit, amplify it and then feed it back into the LC circuit again. This process can be achieved using a voltage amplifier using an op-amp, FET or bipolar transistor as its active device. If the energy replaced is too large the amplitude would increase until clipping of the supply rails occurs. Alternatively, if the quantity of energy exchanged is not sufficiently large enough, the amplitude would eventually damp out to zero over time and this will result in total loss of positive feedback energy and oscillations would stop

$$
\grave{\omega}=\frac{1}{\mathrm{LC}}
$$


Since $\omega=2 \pi f$

$$
f=\frac{1}{2 \pi \sqrt{L C}}
$$

Where:

- $\mathrm{L}$ is the Inductance in Henries.

- $\mathrm{C}$ is the Capacitance in Farads.

- $f$ is the Output Frequency in Hertz.

\section{METHODOLOGY}

In other to realize this project, Study of existing technology was carried out which include hardware, schematics and existing wireless charger already in market. Proper research into the science of operation of wireless power transfer was carried out. The circuit was designed, modified, simulated and constructed

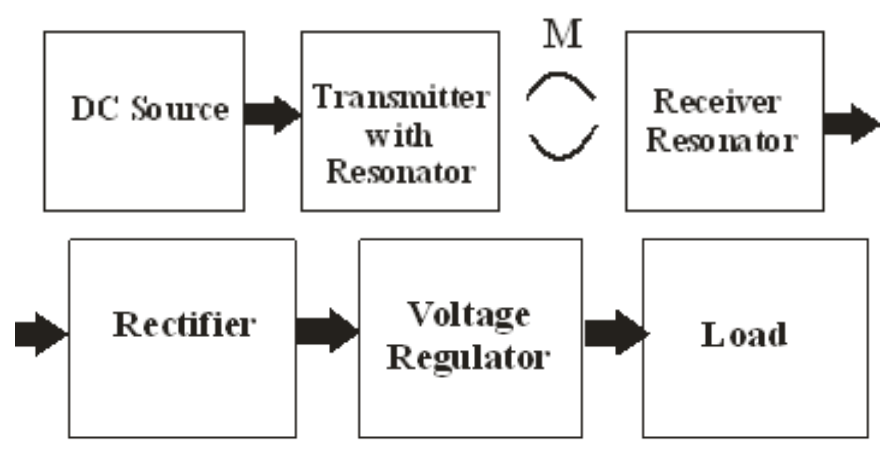

Fig.2. Block Diagram of Prototype Charger

The function of this block is the production of DC source voltage which can be from a car charger or DC battery of $12 \mathrm{~V}$. Transmitter with resonator: a high efficiency push-pull amplifier with LC resonator where the DC voltage is converted to a signal with frequency range between $50-70 \mathrm{kHz}$.

Receiver resonator: the magnetic field produced by the transmitter combines to the receiver resonator, exciting the resonator therefore causing the buildup of energy in it.

Rectifier: the rectifier changes the received AC energy from the receiver power back to dc power. Voltage regulator: the DC rectified voltage is regulated down to $5 \mathrm{v}$ suitable for mobile phones charging.

Output: this stage the energy is combined out of the device resonator to deliver energy, for example, powering a load directly or energy for battery charging.

\subsection{The Source Resonator: The ZVS Driver Oscillator Model}

This project uses a special type of Oscillator called the Zero Voltage Switching ZVS (Mazilli) driver designed by Vladimiro Mazilli ${ }^{[11]}$ as the source resonator. This is a model of the ZVS Oscillator similar to the 
one used to build the circuit is shown in Fig.3.

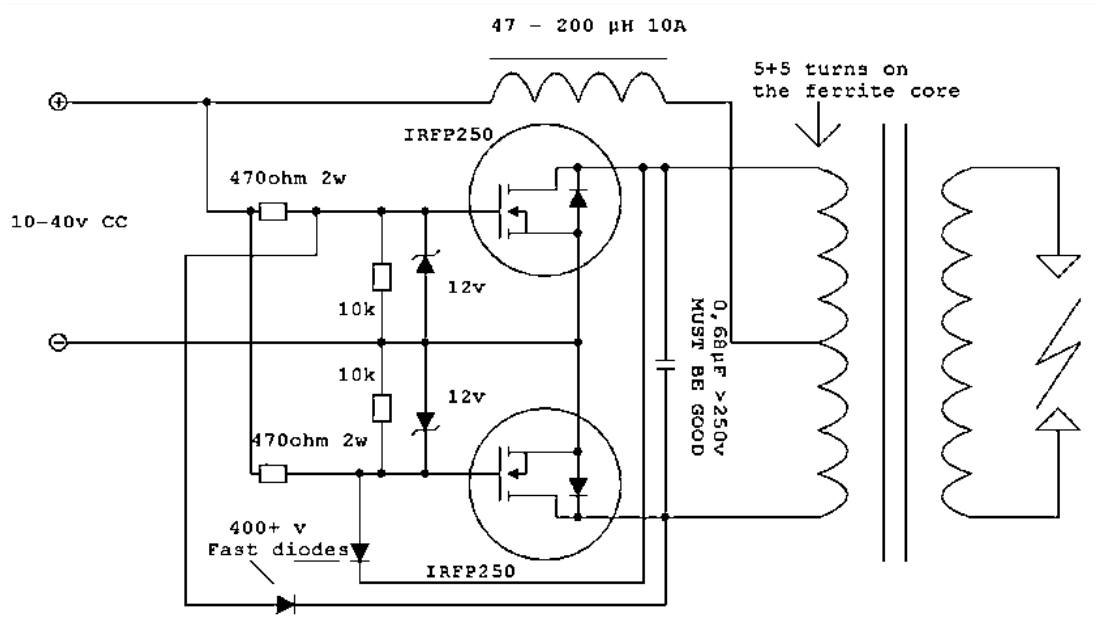

Fig.3. ZVS Mazilli Driver

The ZVS is a push pull oscillator. In its purist sense it would consist of nothing more than two MOSFET, a capacitor, and an inductor L2. The driver depends on the fact that no two components are precisely alike and uses small variances in the internal resistances of the MOSFETs' and other properties to start the oscillation. The inductor L2 prevents AC from getting back to the batteries. The fast diodes prevent the FETS from turning on when they shouldn't and going suicidal.

Excessive voltage may reach the gate of the MOSFETs and destroy them, therefore we need the rest of the supplementary components act as gate protection to make sure these does not happen. In operation the capacitor and inductor form an LC circuit, frequency that the driver operates at can be varied by changing the value of the capacitor and/or the number of turns on the primary.

The zero voltage switching drivers is an inverter and has the benefit that it reduces the harmonic spectrum of any EMI (centering it on the switching frequency) and allows higher frequency operation causing reduced, easier-to-filter noise and the utilization of smaller filter components. ZVS stands for Zero Voltage Switching, which means switching, when voltage is equal to zero, giving no switching losses because the MOSFETs switch when they have zero volts across them. A "ZVS driver" can oscillate a large amount of power with about $90 \%$ efficiency and frequency range between 50-60 kHz. In order to prevent the oscillator from drawing huge peak currents and exploding, L1 is added in series with $+\mathrm{V}$ as a choke. The LC impedance is what limits the actual current (the choke just mitigates current spikes). ${ }^{[1]}$

\subsection{Energy Transfer $Q$ Factor and Efficiency}

The general principle is that if a given oscillating amount of energy (for example a pulse or a series of pulses) is placed into a primary coil which is loaded capacitive; the coil will 'ring', forming an oscillating magnetic field. The energy will transfer back and forth as an exchange between the magnetic field in the inductor and the electric field across the capacitor at the resonant frequency. This oscillation will eventually die away at a rate determined by the gain-bandwidth ( $\mathrm{Q}$ factor).

The primary coil forms a RLC circuit, and the $\mathrm{Q}$ factor for such a coil is: ${ }^{[13]}$ 
$Q=\frac{1}{R} \sqrt{\frac{L}{C}}$

For $\mathrm{R}=10 \Omega, \mathrm{C}=1 \mu \mathrm{F}$ and $\mathrm{L}=10 \mathrm{mH}, \mathrm{Q}$ is given as 10 .

The quality factor is a ratio of the inductance to the resistance. The ratio of energy stores to the ratio of energy loss at resonance

$$
\mathrm{Q}=\frac{\text { Energy Stored }}{[12]}_{\text {Energy Lost }}
$$

To the electronics and communication engineer the degree of predomination of the energy oscillation is important since the better the ratio ofpredominancethen the better the circuit is able to accept current, and the better the current that is delivered to the charging device at the receiver output with power at the resonant frequency .The degree of predominance is given by a factor of goodness termed the $\mathrm{Q}$ factor. The graph of the bandwidth of a parallel resonance circuit is shown below in Fig.4.

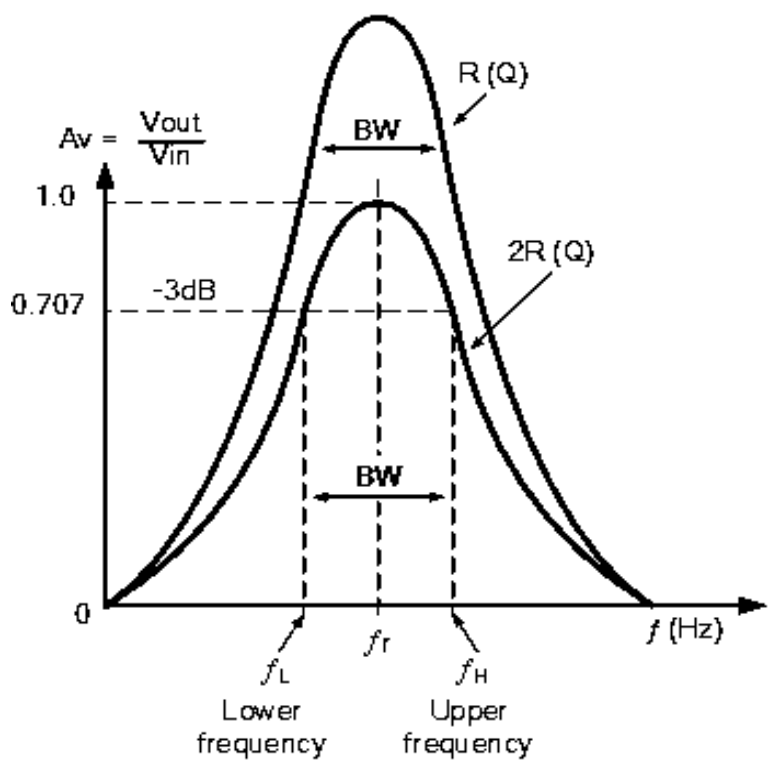

Fig.4. Bandwidth of a Parallel Resonance Circuit

Because from experimental results the $\mathrm{Q}$ factor can be very high, (around a thousand has been verified with air cored coils) only a small percentage of the field has to be coupled from one coil to the other to achieve high efficiency, It can be shown that a figure of merit for the efficiency is

$$
U=K \sqrt{Q_{1}} Q_{2}
$$

where $\mathrm{Q}_{1}$ and $\mathrm{Q}_{2}$ are the $\mathrm{Q}$ factor of the source and receiver coils.

And the maximum achievable efficiency is ${ }^{[14]}$ 


$$
\eta_{o p t}=\frac{U^{2}}{\left(1+\sqrt{1+U^{2}}\right)^{2}}
$$

\subsection{Construction of the Transmitter}

The Mazzilli ZVS driver is used due to its simplicity. However, in this case, the reason it works is because the ZVS driver begins by oscillating at around $50-60 \mathrm{khz}$. Since the objective is to build a transmitter resonator with frequency range of $50-70 \mathrm{kHz}$ The ZVS Mazilli oscillator design is suitable, and also turn on and off when the voltage across them is zero. (Meaning, they generate little/no heat due to switching losses). The transmitter is made up of DC source, inverter and resonant tank circuit as shown in Fig.5

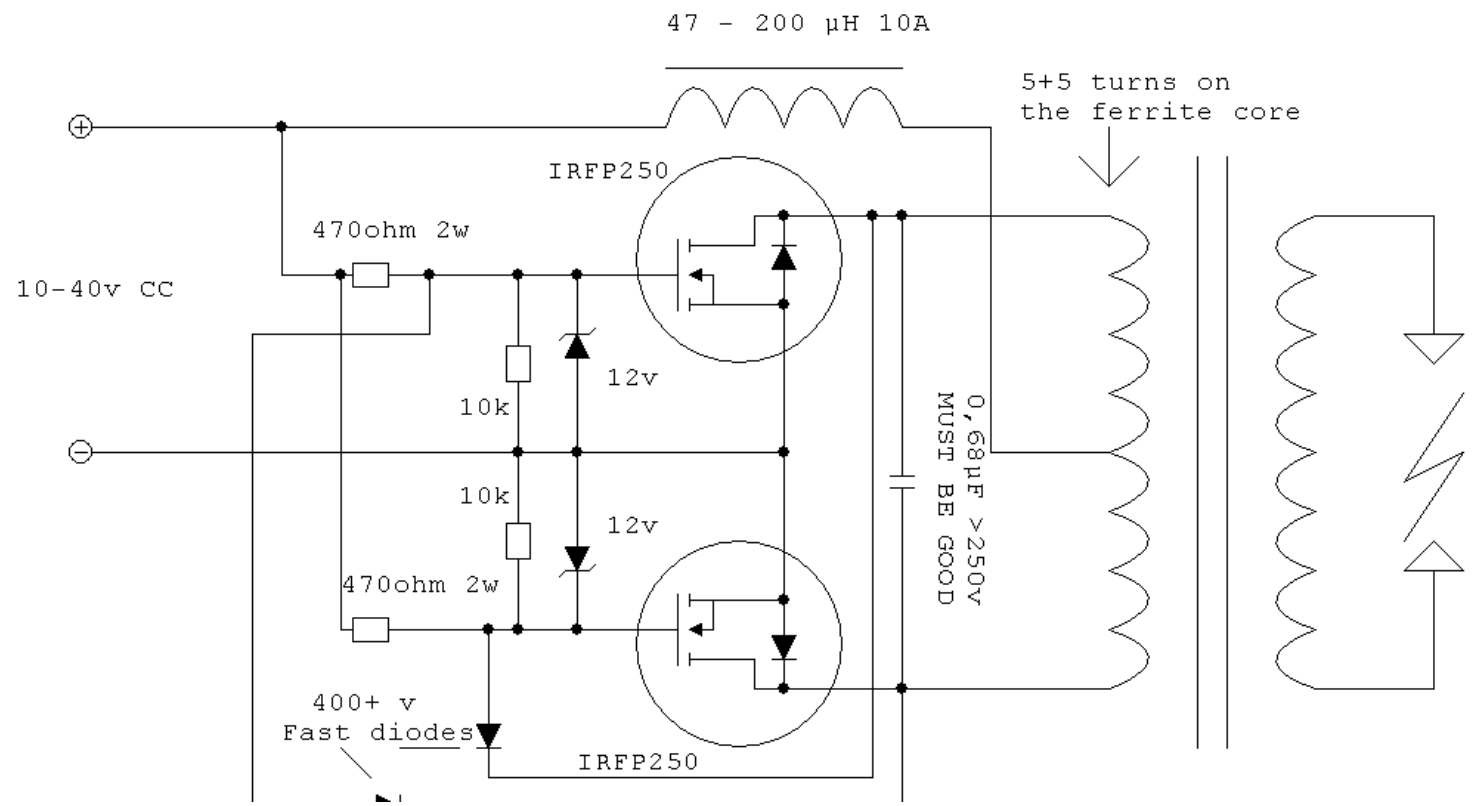

Fig.5. Circuit Diagram of the Mazzilli ZVS Driver

\subsection{Constructing the $2.8 \mu H$ Inductor}

The main aim to get the number of turns that will produce an inductance of $2.8 \mu \mathrm{H}$

Length $=3.14$ inches i.e. $0.0797 \mathrm{~m}$ and

Diameter $=0.045 \mathrm{~m}$

An approximation of inductance for any coil can be found with this formula $[13,14]$

$$
L=\frac{N^{2} \mu A}{l} \ldots
$$




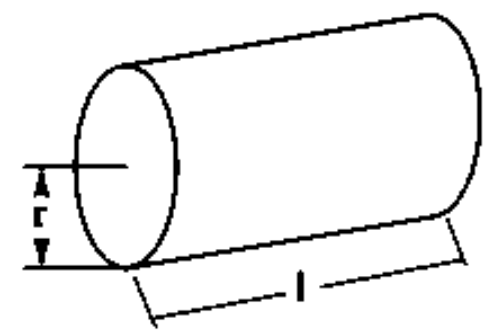

Fig.6.

$\mathrm{L}=$ Inductance of coil in henrys

$\mathrm{N}=$ Number of turns in wire coil (Straight wire $=1$ )

$\mu_{\mathrm{r}}=$ Permeability of core material (absolute not relative)

$\mu_{\mathrm{o}}=$ Relative permeability, dimensionless

$(\mathrm{u}=1.26 \times 10-6 \mathrm{~T}-\mathrm{m} /$ At permeability of free space

$\mathrm{A}=$ Area of coil in square meter $=A=\pi r^{2}$

$\mathrm{I}=$ Average length of coil in meters

\section{The Parameters}

- Diameter $=0.045$ meters

- Radius $=0.0225$ meters

- $\mathrm{A}=\mathrm{area}=\pi \mathrm{r}^{2}=3.142 * 0.0025^{2}=1.59 * 10^{-3} \mathrm{~m}^{2}$

- $\mu_{\mathrm{o}}=4 \pi^{*} 10^{-7} \mathrm{H} \cdot \mathrm{m}^{-1}$

- $\mu_{\mathrm{r}=1}$

- $1=0.0797$ meters

Calculating for $\mathrm{N}$ we get $\mathrm{N}=11$ turns.

Figure 7 shows the Prototype construction

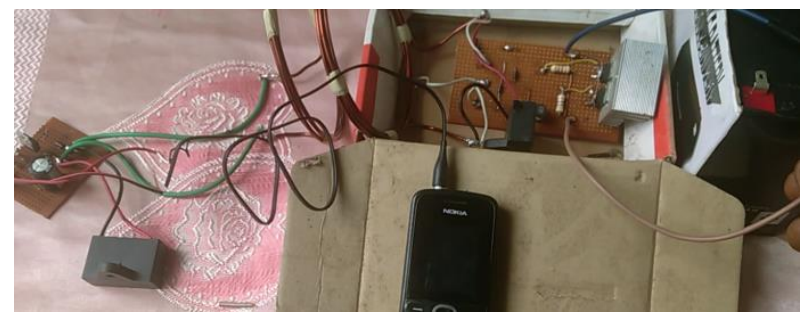

Fig.7. Prototype Design

\section{Discussion of Results}

For inductive charging to work, the transmitter must produce sufficient resonating voltage waveform capable of transferring energy across air gap to induce EMF in the secondary or transmitter coil.

Fig.9 shows the transmitter output waveform. This waveform is produces from the ZVS resonator discussed earlier while using a $2 \mu \mathrm{F}$ capacitor. 


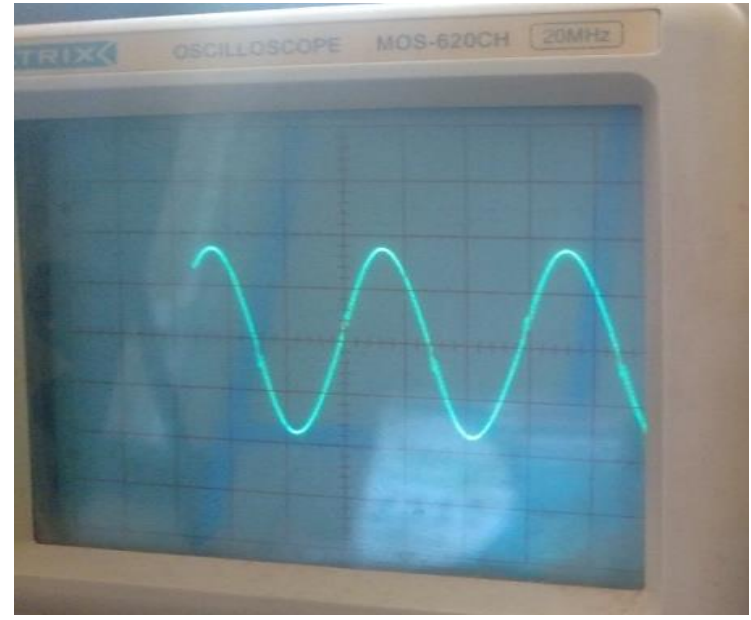

Fig.8. Transmitter Output Waveform

The measured resonance frequency from the oscilloscope is

$$
\begin{aligned}
& \mathrm{T}=15 \mu \mathrm{s} \times .5=15 \mu \mathrm{s} \\
& f=\frac{1}{T}=66.66 \mathrm{KHz}
\end{aligned}
$$

While the calculated resonance frequency is

$$
f_{t}=67.255 \mathrm{KHz}
$$

The Voltage measurement from the oscilloscope is

$$
3.6 \times 0.5=1.8 \times 10 \text { (Magnification factor) }=18 \text { Volts }_{\mathrm{pk}-\mathrm{pk}} \text {. }
$$

This implies $18 \mathrm{~V}$ will be produced at the transmitter and will travel across the airgap to induce EMF in the receiver circuit.

At the receiver, the frequency waveformis shown in Fig.4.2

$$
\begin{gathered}
5 \mu \mathrm{s} \times 3=15 \mu \mathrm{S} \\
f_{r}=1 / \mathrm{T}=66.66 \mathrm{KHZ}
\end{gathered}
$$

We can see that $f_{t}=f_{r}$ i.e frequency at transmitter is equal to frequency at receiver.

Then the voltage induced at the receiver is

$$
3 \times 0.2=0.6=6 \text { Volts }_{\text {pk-pk }} \text { output }
$$


This shows a voltage drop from $8 \mathrm{~V}$ to $6 \mathrm{~V}$ which is a result of flux wastages.

Fig 9 shows the receiver voltage.

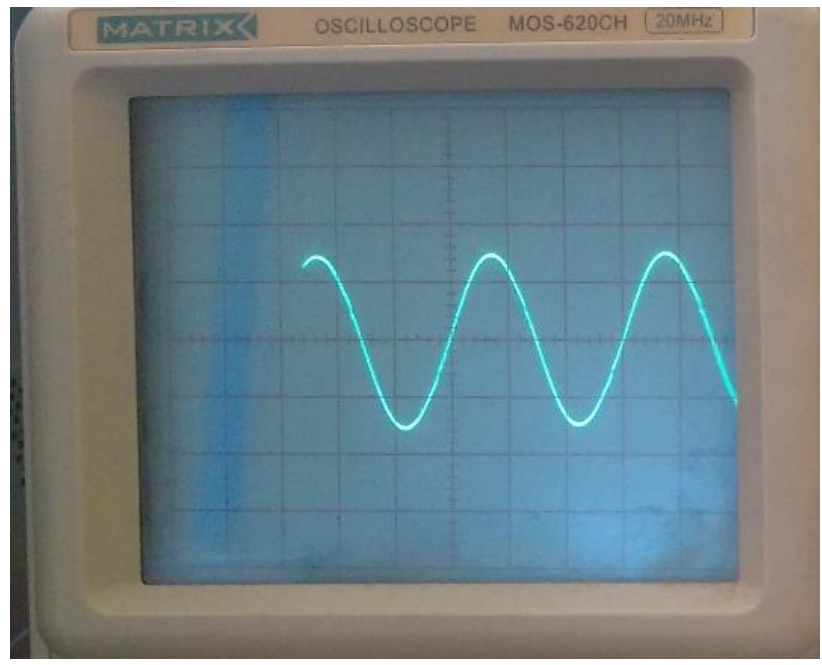

Fig.9. Receiver Output Waveform.

\subsection{Waveform after Rectification}

Since the energy generated is to be used to charge mobile phones which utilized DC batter source, the output from the receiver needs to be rectified

The waveform after rectification is shown below Fig.10

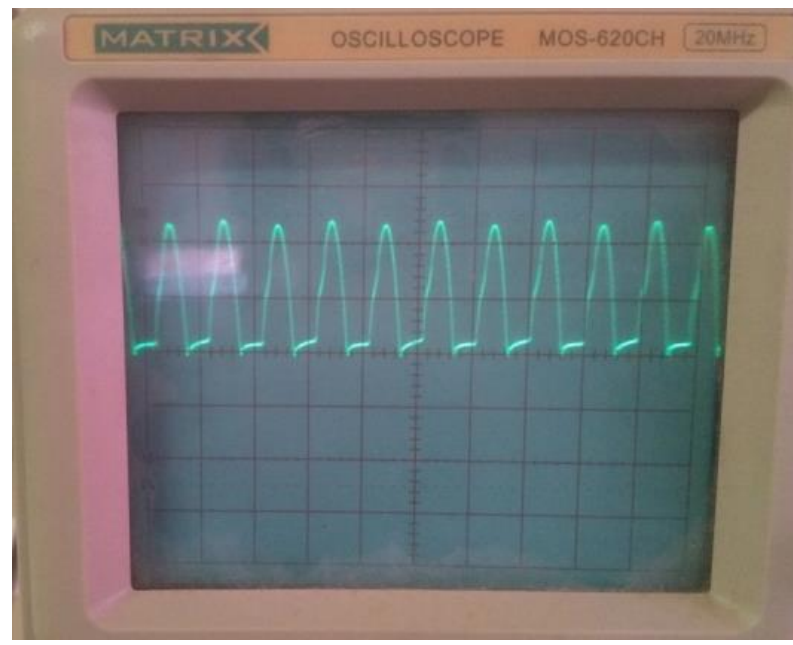

Fig.10. Receiver Output Waveform after Rectification.

The waveform has a lot of ripples and hence needs to be filtered and further regulated. The DC voltage after filtering and regulation is shown in Fig. 11 below 


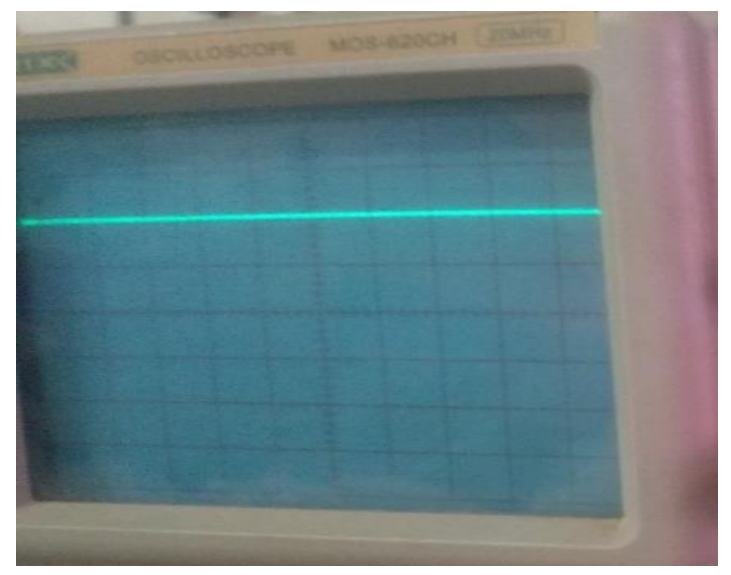

Fig.11. Receiver waveform after Filtering and Regulation

\subsection{Analysis of Voltage at the Receiver}

1. Due to resonance the AC voltage is expected to rise gradually with time.

2. The circuit is capable of DC input voltage of between $12 \mathrm{~V}$ to $24 \mathrm{~V}$ therefore the higher the input voltage the higher the voltage induced at the receiver (but if the DC voltage after rectification exceeds $18 \mathrm{~V}$ entering into the regulator, it may damage the Voltage regulator)

3. Distance of separation between transmitter and receiver also determines the value of induced EMF at the receiver as flux linkages reduced with distance.

A voltage of $4-5 \mathrm{~V}$ is required to charge the phone. The voltage drop of the regulator is about $2 \mathrm{~V}$ so hence a Voltage of $6 \mathrm{~V}$ into the regulator will still function.

\subsection{Analysis of End-to-end Coupling Distance}

Table 1 shows the distance between transmitter and receiver of the prototype charger and the measures DC output voltage and current.

Table 1.

\begin{tabular}{l|l|l|l|l}
\hline Distance in $\mathrm{cm}$ & DC Input Voltage & $\begin{array}{l}\text { Receiver rectified } \\
\text { output voltage }\end{array}$ & $\begin{array}{l}\text { DC Regulated } \\
\text { Output Voltage }\end{array}$ & $\begin{array}{l}\text { DC Current through a } \\
\text { Gionee E7 mobile } \\
\text { phone }\end{array}$ \\
\hline $1-2 \mathrm{~cm}$ & $12 \mathrm{~V}$ & $10 \mathrm{~V}$ & $5.05 \mathrm{~V}$ & $0.2 \mathrm{~A}$ \\
\hline $3 \mathrm{~cm}$ & $12 \mathrm{~V}$ & $6.8 \mathrm{~V}$ & $4.01 \mathrm{~V}$ & $0.18 \mathrm{~A}$ \\
\hline
\end{tabular}

\section{Conclusion}

The project was successfully constructed using different components, and selecting the ones with optimal performance.

Tests were carried out and measurements were taken of output waveforms, to ensure that the required frequency was generated.The voltage level was achieved, and there was adequate current to charge the test phones. 
The prototype was used to charge mobile phones to confirm its functionality and usability and it functioned as expected although with some limitations.

\section{Limitations}

1. The maximum achievable distance between transmitter and receiver is about $3 \mathrm{~cm}$.

2. The resonant capacitor experienced heating which made it difficult for to connect the device more than few seconds. This is due to the fact that I could not get capacitors with the proper current handling capacity.

3. The project is not miniaturized and not portable.

4. Losses in the form of heating of the Coil and due to unguided radiation of EM waves there are a lot of flux wastages.

\section{Recommendations}

It is recommended that this design should be well improved upon to achieve the three major limitations stated in the above.

The distance of power transfer can be increased by increasing the resonance frequency and also the input voltage.

It is recommended that electronic oscillators IC can be used to generate EM waves at higher frequencies to extend the range of power transfer. A low-power LTC6900 oscillator that oscillates at a frequency of $606 \mathrm{kHz}$ can be used in future development and improvement of this project. The use of such IC will also ensure the miniaturization of the design and lesser power will be used to drive the oscillator. Efficiency is improved by decreasing the resistance of the inductive coils since resistance disperses power as heat.

Certain technologies like UBeam [15] are being developed to ensure directivity.UBeam is a device that uses ultrasonic waves to charge multiple devices, from phones to computers, wirelessly. [22]

The aim of this project was achieved. Wireless power transfer is an interesting ongoing area of scientific research due to its prospect of creating convenient way of charging.

Companies like Witricity, ProxiInc, Microsoft Nokia and Ubeam are developing various technologies to improve this technology and also Nissan and Siemens are working on wireless power transfer for use in electric cars to ensure cars charge while in motion. The success of this technology will be a breakthrough in the area of clean energy transfer.

\section{References}

[1] Bahrat International Journal of Engineering Trends and Technology (IJETT) - Volume4Issue4- April 2013 ISSN: 2231-5381 http://www.ijettjournal.org Page 1054 Inductive Charging Technique BasharatNizam K L.

[2] Ibrahim YehyaDallalBaship-ISSN: $\quad 2168-5037 \quad$ e-ISSN: $\quad 2168-5045, \quad 2017 ; \quad 7(2): \quad 31-37$, doi:10.5923/j.ijea.20170702.02 Scientific \& Academic Publishing. All Rights Reserve, d2017

[3] Elizabeth Sebastian, Biji B, Pranav V, Rahul A P, Vishnu N Nair ;International Journal of Advanced Research in Electrical, Electronics and Instrumentation Engineering (An ISO 3297: 2007 Certified Organization) Vol. 3, Issue 5, May 2014

[4] Morris, k.(2013). Highly Resonant Wireless Power Transfer: Safe, Efficient, and over Distance, [Online].Available at:http://www.witricity.com/assets/highly-resonant-power-transfer-kesler-witricity2013.pdf [Accessed 15 October 2014].

[5] Wikipedia. (2010). Faraday's law of induction. [ONLINE] Available at:http://en.wikipedia.org/wiki/Faraday\%27s_law_of_induction. [Accessed 23 October 14]. 
[6] Howstuffworks. (2014). How Wireless Power Works. [ONLINE]Available http://en.wikipedia.org/wiki/Faraday\%27s_law_of_induction. [Accessed 23 October 14]

[7] Coefficient of coupling. Coefficient of coupling [ONLINE] Available at: http://www.tpub.com/neets/book2/5f.htm [Accessed 06 October 14].

[8] Theraja, A.K, Theraja, B.L, (2005). A textbook of Electrical Technology.5th edition. India: S.chand and company ltd.

[9] Electronics-tutorials. (2013). Mutual Inductance of Two Coils. [ONLINE] Available at: http://www.electronics-tutorials.ws/inductor/mutual-inductance.html. [Accessed 06 October 14]

[10] Wikipedia. 2014. Electronic oscillator. [ONLINE] Available at: http://en.wikipedia.org/wiki/Electronic_oscillator. [Accessed 03 November 14].

[11] Adams munich. (2010). ZVS (Mazilli) Driver. [ONLINE] Available at: http://adammunich.com/zvsdriver/. [Accessed 09 October 14].

[12] Wikipedia. (2013). Resonant Inductive Coupling. [ONLINE] Available at:http://en.wikipedia.org/wiki/Resonant_inductive_coupling. [Accessed 10 October 14].

[13] Raftabtronics. (2009). Inductor Basics. [ONLINE] Available at:http://www.raftabtronics.com/TECHNOLOGY/ElectromagneticBasics/InductorBasics/tabid/109/Defa ult.aspx. [Accessed 15 October 14].

[14] Wikipedia. (2013). Resonant Inductive Coupling. [ONLINE]Available at:http://en.wikipedia.org/wiki/Resonant_inductive_coupling. [Accessed 10 October 14].

[15] Nick Bilton. (2014). Wireless charging, at a Distance, Moves Forward for uBeam. [ONLINE] Available at: http://bits.blogs.nytimes.com/2014/08/06/ubeam-technology-will-enable-people-to-charge-devicesthrough-the-air/?_r=0. [Accessed 05 November 14].

\section{Authors' Profiles}

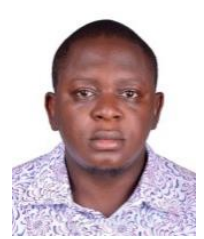

Oluseun Oyeleke is a Master degree holder in Electronics and communication Engineering and a current $\mathrm{PhD}$ Student in Telecommunication. He's focus is on wireless communication, Massive MIMO, MIMO and Machine learning for wireless telecommunication. He is currently an academic staff with the Air force Institute of Technology, Kaduna Nigeria. contactseun@gmail.com

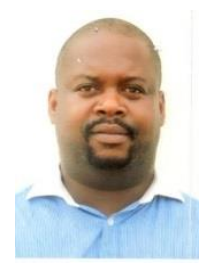

Sadiq Thomas was born in 1980, and is a Senior Lecturer, he has several years' experience in academics from time spent completing his BEng in Computer Engineering and Numerical Modelling of EMATs his PhD Thesis. He has post-doctoral research and lecturing posts at various universities in the UK and Nigeria. HE completed his $\mathrm{PhD}$ in 2009 and his research was based on comprehensive finite element modelling of Electromagnetic Acoustic Transducer sensors used for Nondestructive testing of conductive materials particularly useful for pipeline maintenance.

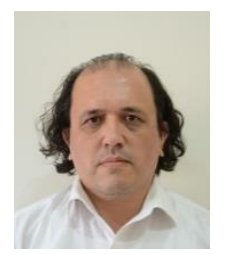

Dr. Gokhan Koyunlu Has a Phd in applied Mathematics (2014).He attended Faith University / Istanbul with specialty in Fractional Conformable Partial Differential Equations, Nonlinear systems over signal and Systems, Modeling and Simulation. 
Dr Petrus Nzerem, DOB: 19 May 1980; Universities attended, Federal University of Technology Owerri 1998 - 2004 (BEng Polymer and Textile Engineering). University of Leeds, 2005 - 2006 (MSc Energy and Environment) University of Manchester 2008 - 2013 Chemical Engineering and Analytical Science.

How to cite this paper: Oluseun D Oyeleke, Sadiq Thomas, Petrus Nzerem, GokhanKoyunlu,"Design and Construction of a Prototype Wireless Power Transfer Device", International Journal of Engineering and Manufacturing(IJEM), Vol.9, No.2, pp.16-30, 2019.DOI: 10.5815/ijem.2019.02.02 